\title{
Comparative Study on Nitrogen Assimilation and Gene Regulation of different Kentucky bluegrass Cultivars in response to Nitrate supply
}

sun xiaoyang

Northeast Agricultural University

Chen Yajun ( $\square$ chenyajun622@163.com )

Northeast Agricultural University

\section{Research article}

Keywords: Kentucky bluegrass, Nitrogen use efficiency, Nitrate supply, Physiological, Transcriptome

Posted Date: July 16th, 2020

DOI: https://doi.org/10.21203/rs.3.rs-41819/v1

License: (c) (i) This work is licensed under a Creative Commons Attribution 4.0 International License.

Read Full License 


\section{Abstract}

Background: Kentucky bluegrass (Poa pratensis $\mathrm{L}$ ) is one of the most popular cool-season turfgrass worldwide, but the mechanisms of this species in response to low nitrogen $(\mathrm{N})$ still remain unclear. In this study, we characterized two cultivars 'Bluemoon' and 'Balin' distinctly in morphological, chromosomal, physiological and molecular attributes to $\mathrm{N}$ supply.

Results: Bluemoon was more tolerant to low N than Balin by exhibiting higher turf quality (TQ), photosynthetic ability, activities of $\mathrm{N}$ reductases and synthetases and nitrogen use efficiency (NUE). Gene expression profiling showed that there were 968 and 336 differentially expressed genes (DEGs) after eliminating genetic background differences in Bluemoon and Balin respectively during low $\mathrm{N}$ stress, and these DEGs highly enriched in 'Nitrogen metabolism', 'Pyruvate metabolism' and 'Carbon fixation in photosynthetic' pathways. The identified genes related to carbon (C) metabolism highly expressed in Bluemoon, which could generate more NADPH then result in more $\mathrm{N}$ reduction comparing with Balin. Moreover, R2R3-MYB transcription factors were predicted to bind the promoter of GS to enhance the efficiency of GS/GOGAT cycle.

Conclusion: These results could be crucial molecular regulations for improving the tolerance to low $\mathrm{N}$ and NUE in Bluemoon. The climate and geography in origins may shape the $\mathrm{N}$ assimilation patterns in Kentucky bluegrass via long-term domestication. Taken together, the findings help elucidate the low $\mathrm{N}$ tolerance mechanisms in Kentucky bluegrass and would be valuable for the genetic improvement of NUE aiming to promote low-input turfgrass management.

\section{Introduction}

Kentucky bluegrass $(\mathrm{KB})$ is one of the most famous and popular cool-season turfgrass widely used in the temperate and cold temperate zones, and even in polar regions [1]. It has excellent aesthetic appeal due to a combination of softness, medium to fine-leaf texture, dark green color, and persistence. Nearly every characteristic needed for an ideal turf is present in the KB [2]. Nevertheless, the developments of numerous tillers and shoots in KB clonal system connected by rhizomes largely rely on nitrogen $(\mathrm{N})$ availability in soil and efficient $\mathrm{N}$ assimilation in plants [3]. Reasonable $\mathrm{N}$ application will provide attractive turf and landscape, while inadequate $\mathrm{N}$ application will negatively affect turfgrass growth rate, tillers density, photosynthesis and turf quality [4]. Although various techniques have been used in turf management over the past few decades to improve high NUE and maintain turfgrass quality [5], few information is available on improving KB with characteristics of low $\mathrm{N}$ demand. Therefore, development of KB germplasm with improved NUE and less N-requirement is crucial to help mitigate $\mathrm{N}$ loss from soil, reduce the impacts of non-utilized $\mathrm{N}$ on the environment, and minimize costs for grass management [6].

$\mathrm{N}$ metabolism is one of the basic physiological processes that control many cellular activities in plants [7]. Plants absorb $\mathrm{N}$ either as nitrate or ammonium, and then convert them to various amino acids [8]. The activities of $\mathrm{N}$ assimilating enzymes play a significant role in maintaining plant growth and development 
[9]. Nitrate reductase ( $\mathrm{Nr}$ ), nitrite reductase (NiR), glutamine synthetase (GS), glutamate synthetase (GOGAT), and aspartate aminotransferase (AspAT) are key enzymes involved in N metabolism, and activities of these enzymes represent the status of plant $\mathrm{N}$ metabolism $\left[{ }^{10}\right.$. Nitrate $\left(\mathrm{NO}_{3}{ }^{-}\right)$reduction to $\mathrm{NH}_{4}{ }^{+}$is mediated by $\mathrm{Nr}$ and $\mathrm{NiR}$; and $\mathrm{NH}_{4}{ }^{+}$is then converted by $\mathrm{GS}$ to glutamine (Glu). The $\mathrm{N}$ compound of Glu is an important precursor for synthesis of $\mathrm{Chl}$ protein and other $\mathrm{N}$-containing metabolites used for plant growth and development [11]. Based on former studies, there were significant differences among cultivars of KB for $\mathrm{N}$ acquisition and retention, and NUE was negatively correlated with ambient $\mathrm{N}$ levels, $\mathrm{N}$ uptake rate and nitrate activity [12-13]. $\mathrm{Nr}$ and NiR activity also varied largely in KB cultivars and responded strongly to ambient $\mathrm{N}$ levels [14]. Although most of these researches revealed the $\mathrm{N}$ metabolism in KB based on physiological changes, the findings are valuable for selecting less $\mathrm{N}$-requiring cultivars.

Plants have both high- and low- affinity $\mathrm{N}$ transport systems (NRT) [15]. Numerous $\mathrm{NO}_{3}{ }^{-}$transporters have been found at the transcriptional level from a variety of plant species with a function of improving NUE [16]. Inorganic $\mathrm{N}$ is absorbed and transported by NRT genes into plants for further organically incorporated into glutamine (Glu), glutamate (GIn), asparagine and aspartate via the interconnected metabolic systems of the carbon and $\mathrm{N}$ assimilation. The energy of NADH and ATP for N metabolism is directly or indirectly derived from the processes of $\mathrm{Pn}$, glycolysis and respiration $[17,18]$. A large number of functional genes were revealed in participating in these interdependent processes, like those encoding NR, NiR, GS, GOGAT, GDH, OGDH (2-oxoglutarate dehydrogenase), ENO (enolase), MDH (malate dehydrogenase) and AspAT (aspartate aminotransferase) [19-20]. In addition, transcription factors have shown to play a role in $\mathrm{N}$ metabolism [21]. For example, $R 2 R 3-M Y B$ transcript factors in $M Y B$ subfamily specifically occupied the promoter regions of $\mathrm{N}$ assimilation genes, such as CmNRT, CmNIR and CmGS, and their transcript expression patterns were same as those genes, indicating MYB transcript factors involved in plant metabolism $[19,22]$. Moreover, transcriptomics has been applied to study the drought and salt stress of KB [23-24]; but to the best of our knowledge, research on the regulation of $N$ assimilation and metabolism at transcript level remains scant in KB.

In the current study, two $\mathrm{N}$ responsive cultivars, Bluemoon and Balin, were used for studying low $\mathrm{N}$ tolerance mechanisms. We examined morphology, microscopic chromosomal characteristics, and photosynthesis, chlorophylla (Chla) fluorescence and activities of enzymes associated with $\mathrm{N}$ assimilation, and NUE under low $\mathrm{N}$ stress. Furthermore, we used transcriptome sequencing to find genes relation to $\mathrm{N}$ and carbon-nitrogen ( $\mathrm{C}-\mathrm{N}$ ) metabolism in $\mathrm{KB}$ and validated gene expression in the selected key genes. Our results will reveal the physiological and molecular mechanisms of low $\mathrm{N}$ tolerance in $\mathrm{KB}$, providing valuable resources for genetic improvement of high NUE in KB and related plant species.

\section{Materials And Methods}

- 1.1 Plant materials and growing conditions 
Based on previous assessment on the $\mathrm{N}$ response for $\mathrm{KB}$ (Table S1), two cultivars differing in requirement for $\mathrm{N}$, Bluemoon, which was better tolerant to low $\mathrm{N}$ conditions, and Balin, which preferred high $\mathrm{N}$ supply, were selected for this study. Two-year-old sods of these two cultivars were collected from field plots at Horticulture Experiment Station of Northeast Agricultural University (Harbin, China; $128^{\circ} 04^{\prime} \mathrm{E}, 44^{\circ} 50^{\prime} \mathrm{N}$ ). The soil was black loam containing $48.6 \mathrm{~g} \mathrm{~kg}^{-1}$ organic matter and was neutral with a pH of 7.0. The soil around root zone areas was removed to before sods were planted in PVC pots $(13 \mathrm{~cm}$ in diameter and $40 \mathrm{~cm}$ in height with holes at the bottom for drainage) filled with sand-vermiculite $(2: 1 \mathrm{v} / \mathrm{v})$ mixture. Plants were established for $30 \mathrm{~d}$ in a greenhouse maintained at average day/night temperatures of $25 / 20$ ${ }^{\circ} \mathrm{C}$ and an average $12 \mathrm{~h}$ light period at $720 \mu \mathrm{mol} \cdot \mathrm{m}^{-2} \mathrm{~s}^{-1}$ photosynthetically active raditaion (PAR). Grasses were trimmed weekly to about $6 \mathrm{~cm}$, watered every $2 \mathrm{~d}$, and were fertilized once a week with $60 \mathrm{~mL}$ full-strength Hoagland solution [25] (Hoagland, 1950).

- 1.2 Treatments and experimental design

Three weeks before the imposition of $\mathrm{N}$ treatments, all pots were transferred to a growth chamber for acclimation under $25 / 20{ }^{\circ} \mathrm{C}$ (day/night), $65 \%$ relative humidity, and a $12 \mathrm{~h}$ illumination at $500 \mu \mathrm{mol} \cdot \mathrm{m}^{-}$ ${ }^{2} \mathrm{~s}^{-1}$ PAR. Two weeks after adaptation, plants were rinsed with deionized water for one week, and were then exposed to two levels of $\mathrm{N}$ treatments: 1) low $\mathrm{N}$ treatment with $0.5 \mathrm{mM} / \mathrm{L} \mathrm{NO}_{3}{ }^{-}$in Hoagland solution; and 2) sufficient $\mathrm{N}$ treatment with optimal $\mathrm{N}$ of $15 \mathrm{mM} / \mathrm{L} \mathrm{NO}_{3}{ }^{-}$. The imposed two levels of $\mathrm{N}$ concentrations in this experiment were based on $\mathrm{N}$ absorption and $\mathrm{N}$ accumulation in two cultivars (Fig. 1d). Tubes under low-N and high-N treatment received $60 \mathrm{~mL}$ of $\mathrm{N}$ solution every other day, respectively. Two treatments for each cultivar had three replicates (three pots) and were arranged in a completely randomized design. After 21 days of $\mathrm{N}$ treatment, leaf samples were collected and immediately stored at $-80^{\circ} \mathrm{C}$ for biochemical measurements and RNA extraction. RT-qPCR was performed in three independent biologicals and three technical replicates.

- 1.3 Measurements

- 1.3.1 Morphology, chromosome, and plant growth

Plant height of the two cultivars was measured with a ruler as the average of ten plants in the field in June 2018 for calculating the growth rate. Leaf color was measured by SPAD502 (Konica Minolta, Japan). The chromosome numbers in the cells of root tips were examined by the 'FISH' method [26]. The visual rating scales for turf quality was from 1 to 9 , with 1 being very poor, 9 being excellent, and 6 being the lowest acceptable value [27].

- 1.3.2 $\mathrm{N}$ content and physiological measurements

The $\mathrm{N}$ content in leaf samples was determined by the elemental analyzer (Vario EL III, German ELEMENTAR company). The samples were placed in an oven and dried at $85^{\circ} \mathrm{C}$ to a constant weight, ground into uniform powder with a mortar. A $10 \mathrm{mg}$ powder was wrapped in a tin boat and placed in a sample tray, then poured it into the combustion tube and instantaneously burnt under high temperature 
$\left(1800^{\circ} \mathrm{C}\right)$ and oxygen-rich conditions. $\mathrm{N}$ content was obtained and NUE was calculated according to the method of Almeida et al. (2018) with a minor modification [28]. Namely, NUE (gDW.gN $\left.{ }^{-1}\right)=$ leaf dry weight (g) /leaf $\mathrm{N}$ accumulation (g).

Enzymes assays were performed as following steps. For measuring $\mathrm{Nr}$ and $\mathrm{NiR}$, fresh leaves $(0.3 \mathrm{~g})$ were homogenized in a chilled mortar and pestle with $0.1 \mathrm{M}$ potassium phosphate buffer $(\mathrm{pH} 7.4)$ containing $7.5 \mathrm{mM}$ cysteine, $1 \mathrm{mM}$ EDTA, and 1.5\% (w/v) casein. The homogenate was centrifuged at $10000 \times \mathrm{rmp}$ for $10 \mathrm{~min}$ at $4{ }^{\circ} \mathrm{C}$. Nr activity was determined according to the method of Jiang ${ }^{14}$, and absorbance of the supernatant was determined at $520 \mathrm{~nm}$. NiR was assayed using the method of Ozawa [29], and absorbance of the supernatant was determined at $530 \mathrm{~nm}$. For measuring GS, fresh leaves $(0.3 \mathrm{~g})$ were homogenized in $50 \mathrm{mM}$ Tris- $\mathrm{HCl}(\mathrm{pH}$ 7.8) containing 15\% (v/v) glycerol, $14 \mathrm{mM}$ 2-mercaptoethanol, $1 \mathrm{mM}$ EDTA, and $0.1 \%(\mathrm{v} / \mathrm{v})$ Triton X-100 in cool condition. The homogenate was centrifuged for $15 \mathrm{~min}$ at $10000 \times$ rmp at $4^{\circ} \mathrm{C}$. The supernatant was used as an enzyme extract. GS activity was measured by the method of Zhang [30], and absorbance was read spectrophotometrically at $540 \mathrm{~nm}$. For measuring GOGAT, $1 \mathrm{~g}$ of fresh leaves was cut and then pre-cooled with $4 \mathrm{~mL}$ of $0.05 \mathrm{~mol} / \mathrm{L}$ Tris-HC1 buffer (pH 7.6), and ground in an ice bath for $10 \mathrm{~min}$ [31]. The mixture contained $0.4 \mathrm{~mL}$ of $20 \mathrm{mmol} / \mathrm{L} \mathrm{L}$-glutamine, $0.5 \mathrm{~mL}$ of $20 \mathrm{mmol} / \mathrm{L}$ a-ketoglutaric acid, $0.1 \mathrm{~mL}$ of $10 \mathrm{mmol} / \mathrm{L} \mathrm{KCl}, 0.2 \mathrm{~mL}$ of $3 \mathrm{mmol} / \mathrm{L} \mathrm{NADH}$ and $0.3 \mathrm{~mL}$ crude enzyme extract in a total volume of $3.0 \mathrm{~mL}$. After the reaction was started, an extinction value was recorded every $20 \mathrm{~s}$ at $340 \mathrm{~nm}$ for 11 times. The enzyme activity was measured by taking a period in which the optical density was stably decreased.

Chlorophylls (including Chla and Chl $b$ ) were extracted in $80 \%(\mathrm{v} / \mathrm{v})$ acetone from leaves $(0.3 \mathrm{~g})$ until the leaf fragments bleached to white. The absorbance was measured using a spectrophotometer (T6 New Century, Beijing, CN) at $665 \mathrm{~nm}$ and $649 \mathrm{~nm}$. The total Chl content was calculated using the equation of Lichetenthaler [32].

Leaf Chla fluorescence were measured at the end of treatments using a IMAGING-PAM fluorometer (Zealquest, Shanghai, China). The second expanded leaf from the top on three represented plants of two cultivars was chosen for the determination of parameters under different treatments [32]. The formula of $\mathrm{Fv} / \mathrm{Fm}$ was $\mathrm{Fv} / \mathrm{Fm}=(\mathrm{Fm}-\mathrm{Fo}) / \mathrm{Fm}$ represents the maximal quantum yield of PS区. Nonphotochemical quenching (NPQ) was calculated automatically by the IMAGING-WIN software. Gas exchange of a fully expanded leaf was measured from 8:00 AM to 14:00 PM during daytime at the end of $N$ treatments using a portable gas exchange system ( $\mathrm{Li}-6400$, Li-Cor, Lincoln, NE, USA). The temperature and light intensity were set at $30 \pm 5{ }^{\circ} \mathrm{C}$ and $1000 \mu \mathrm{mol}$ (photon) $\mathrm{m}^{-2} \cdot \mathrm{s}^{-1}$. Ambient $\mathrm{CO}_{2}$ concentration were used as reference $(410 \pm 5 \mu \mathrm{mol} / \mathrm{mol})$. Data of photosynthesis rate $(\mathrm{Pn})$ and intercellular $\mathrm{CO}_{2}(\mathrm{Ci})$ of plants were output by Li-6400 system.

- 1.3.3 RNA extraction and transcriptome data processing

Total RNA was extracted from the leaves of Balin and Bluemoon using TRIzol reagent (Invitrogen, Carlsbad, CA, USA). The quality of the RNA samples were confirmed using a NanoDrop ND-8000 
spectrophotometer (NanoDrop, Wilmington, DE,USA), and the samples were sent to the Novogene (Tianjin, China) for RNA sequencing. After libraries constructed, the cDNA was sequenced with a platform of Illumina HiSeq 2000 according to the manufacturer's instructions (http://www.illumina.com).

After filtering raw reads, clean reads were de novo assembled using Trinity [33]. All assembled unigenes were compared with public protein databases, including NR (NCBI non-redundant protein sequence), NT (NCBI nucleotide sequence), KEGG (Kyoto Encyclopedia of Genes and Genomes), Swiss-Prot protein, KOG (euKaryotic Ortholog Groups), InterPro, and GO (Gene Ontology) databases. After obtaining GO annotations for the assembled unigenes, WEGO software was used to determine GO functional classifications for understanding the distribution of unigenes functions [33]. In the final step, KEGG pathway annotations were performed to analyze the metabolic pathways and functions of the unigenes.

- 1.3.4 Promoter cloning and predictive analysis of functional elements

DNA was extracted using CTAB method. Based on the GS fragment (TRINITY_DN111472_c0_g1) from transcriptome (Table S2), three specific primers FA, FB and FC were designed (Table S3). The genomic DNA of KB was used as a template to conduct genome-walking [34]. The PCR product was subjected to agarose gel electrophoresis, and the specific band was gel recovered and sequenced. The primer pairs FS/X (Table S3) for full length promoter amplification were designed according to the results of genomewalking. The reaction procedure was $95^{\circ} \mathrm{C}$ for $10 \mathrm{~min} ; 30$ cycles $\left(95^{\circ} \mathrm{C}\right.$ for $30 \mathrm{~s}, 57^{\circ} \mathrm{C}$ for $30 \mathrm{~s}, 72{ }^{\circ} \mathrm{C}$ for $90 \mathrm{~s}) ; 72{ }^{\circ} \mathrm{C}$ for $5 \mathrm{~min} ; 4^{\circ} \mathrm{C}$ termination. PCR product was purified and ligated to pMD-19T vector, and positive bacterial solution was sequenced. Functional cis-elements of promoter were analyzed using PlantCARE (http://bioinformatics.psb.ugent.be/webtools/plantcare/

$\mathrm{html} /)$.

\subsubsection{Identification Of Differentially Expressed Genes}

The expression abundance of each assembled unigene was calculated using the RPKM (Reads per kilobase per Million reads) algorithm [35]. Statistical comparison of RPKM values between samples were conducted using edgeR software with a false discovery rate $(F D R) \leq 0.05$. All identified DEGs were mapped to each term of the GO and KEGG databases using KOBAS with corrected P-value $\leq 0.05$ to obtain the significantly enriched biochemical pathways. Differentially expressed transcription factors (DETFs) screening cutoffs were FDR $\leq 0.05$ and log2 fold-change $\mathbb{1} 1$. All DEGs were searched in the transcription factor database (PlantTFDB).

\subsubsection{Expression Validation By qPCR}

The expression levels of selected candidate genes from C-N metabolism pathways were validated by qRTPCR using the same RNA samples for the RNA-Seq library construction. Total RNA was isolated from KB leaves and $1 \mu \mathrm{g}$ was reverse-transcribed at $55^{\circ} \mathrm{C}$ by SuperscriptШ. $1 \mu \mathrm{L}$ of a $1: 5 \mathrm{cDNA}$ dilution was amplified by Eco Real-Time PCR System (Illumina) using $1 \times$ Quantimix easy master mix (Biotools) and 
$0.3 \mu \mathrm{M}$ of each primer in a $10 \mu \mathrm{L}$ final volume (Table S3). PCR reaction conditions: $95{ }^{\circ} \mathrm{C}$ for $10 \mathrm{~min}$ for polymerase activation, 45 cycles at $95{ }^{\circ} \mathrm{C}$ for $10 \mathrm{~s}, 57^{\circ} \mathrm{C}$ for $30 \mathrm{~s}$. Gene expressions were normalized against the EF-1a reference gene (Table S3), and the mean normalized expressions and $\log _{2}$ fold-change $\left(\log _{2} \mathrm{FC}\right)$ were calculated by using the Q-Gene program and by the $2^{-\triangle \Delta \mathrm{Ct}}$ method [36], respectively.

- 1.4 Statistical analysis

The data were analyzed using one-way analyses of variance with SPSS v10.0 software (SPSS, Inc., Chicago, IL, United States). The mean values were compared with the least significance difference test at the 0.05 probability level. Figures were plotted using R v3.4.0 and GraphPad Prism v7.00 (Graphpad company, USA).

\section{Results}

- 2.1 Turf appearance, morphology and ploidy

Balin and Bluemoon were obviously different in morphological and chromosomal characteristics. The natural vegetative plant height in Balin was significantly higher than that in Bluemoon, and its growth rate was 8.7 times of Bluemoon (Fig. 1a and 1b). The green intensity of the leaves reflects the quality of the turf. The darker the green leaf color, the higher the satisfaction with the turf quality (Fig. 1e). Data measured by SPAD 502 showed Bluemoon had higher green intensity than Balin (Fig. 1C), which indicated that the turf appearance of Bluemoon was better than Balin. 'FISH' results at the metaphase of mitosis showed that Balin was a hendecaploid with 83 chromosomes, while Bluemoon was a decaploid with 75 chromosomes (Fig. $1 \mathrm{f}$ and $1 \mathrm{~g}$ ).

\subsection{N Content, C/N Ratio And NUE}

Two cultivars showed significant differences in $\mathrm{N}$ accumulation and saturated $\mathrm{N}$ content in leaves when $\mathrm{N}$ supply was higher than $8.0 \mathrm{mM}$ (Fig. 1d). The $\mathrm{N}$ accumulation continued to increase to the maximum until the $\mathrm{N}$ supply concentration was at $15 \mathrm{mM}$, and then the $\mathrm{N}$ content in the leaves remained steady for both cultivars. At this point, $\mathrm{N}$ accumulation in Balin was $81.8 \%$ higher than Bluemoon (Fig. $1 \mathrm{~d}$ ).

Therefore, the concentration of $15 \mathrm{mM}$ could be regarded as the optimal $\mathrm{N}$ supply level for two cultivars. When plants were exposed to low $\mathrm{N}$ condition, the $\mathrm{N}$ content decreased in both cultivars, but the reduction rate of $\mathrm{N}$ content in Balin was greater than that of in Bluemoon. Normally, the $\mathrm{N}$ content in Bluemoon leaves was much lower than that in Balin under the condition of adequate $\mathrm{N}$ supply (Fig. 2a), however, during lower $\mathrm{N}$ process, the losses of $\mathrm{N}$ in Balin was remarkably greater and with the $\mathrm{N}$ content $11.4 \%$ lower comparing with Bluemoon. The ratio of carbon to nitrogen $(\mathrm{C} / \mathrm{N})$ is crucial to reflect the state of plant growth when plant enduring environmental stress. Under optimal $\mathrm{N}$ condition, the ratio of $\mathrm{C} / \mathrm{N}$ in Bluemoon was slightly higher by $3.7 \%$ comparing with Balin, however, after treated with lower $\mathrm{N}$, the ratio of $\mathrm{C} / \mathrm{N}$ increased rapidly and varied significantly in two cultivars (Fig. 3e). Comparing with the optimal $\mathrm{N}$ supply, the average increase of $\mathrm{C} / \mathrm{N}$ ratio in Balin was $36 \%$ higher than that of in Bluemoon. In addition, high NUE after low N stress indicated that Bluemoon possessed the trait of low N requirement (Fig. 2b). 


\subsection{Assay Of Enzymes Activities}

During low $\mathrm{N}$ stress, the $\mathrm{Nr}$ activity in Bluemoon increased fast and evidently differences from other treatments (Fig. 2c), suggesting that $\mathrm{N}$ assimilation in Bluemoon at the $\mathrm{N}$ short stage was more strongly regulated by $\mathrm{Nr}$ than that of in Balin. The activities of NiR and GOGAT were showed in a similar trend with $\mathrm{Nr}$ in different $\mathrm{N}$ treatments. Low levels of nitrogen reduced NiR and GOGAT activities for both cultivars, while the activities of NiR and GOGAT in Bluemoon were 17.3\% and $16.2 \%$ higher comparing with Balin (Fig. $2 \mathrm{~d}$ and 2f). Under optimal $\mathrm{N}$ condition, GS activity was much higher in Balin than that in Bluemoon, however, under low $\mathrm{N}$ situation, GS activity increased in Bluemoon by $48.3 \%$ relative to Balin (Fig. $2 \mathrm{e}$ ).

\subsection{Chlorophyll And Photosynthetic Rate}

Under optimal $\mathrm{N}$ supply, there was no significant difference in Chl content between the two cultivars, the Chl content in Bluemoon was only $1.2 \%$ higher than that of in Balin, but under low $\mathrm{N}$ condition, the decrease of $\mathrm{Chl}$ in Balin was remarkably greater and was $15.6 \%$ lower than Bluemoon (Fig. 3f). Chls are important components in photosynthetic center. Low $\mathrm{N}$ reduced $\mathrm{Pn}$ and $\mathrm{Ci}$, while the rate of $\mathrm{Pn}$ and the concentration of $\mathrm{Ci}$ in Bluemoon were still $29.7 \%$ and $9.8 \%$ greater respectively than that of in Balin

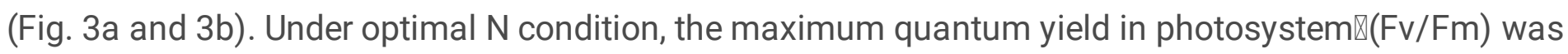
notably higher ( $\mathrm{P} \bowtie 0.05)$ in Balin than in Bluemoon; however, under low $\mathrm{N}$ condition, Fv/Fm was $12.0 \%$ higher and NPQ was 20.1\% lower in Bluemoon than that of Balin (Fig. 3c and 3d).

\subsection{RNA-seq Results}

\subsubsection{Overview the RNA-seq}

To identify the regulatory genes involved in $\mathrm{N}$ assimilation and photosynthesis carbon fixation, we conducted transcriptome sequencing of Balin and Bluemoon leaves. A total of 522,590 unigenes with an average length of 800 bp were achieved (Fig. S1a). The species distribution analysis revealed that KB had a number of homologous sequences in many plant species. The majority of transcripts had a significant level of sequence identity to Brachypodium distachyon, Aegilops tauschii, Hordeum vulgare, which accounted for $19.2 \%, 19.1 \%, 13.9 \%$, of the total transcripts, respectively (Fig. S1b). This result suggested that the genome of Brachypodium distachyon may serve as a reference for the transcriptome analysis of KB. There were 189,919 (36.3\% of all unigenes), 165,273 (31.6\%), 53,260 (10.2\%), 112,180 (21.5\%), 133,162 (25.5\%), 136,033 (26.0\%), and 35,085 (6.7\%) unigenes were found in the NR, NT, KO, SwissProt, PFAM, GO, and KOG databases, respectively. When the sequences were compared with all databases, only $14,672(2.8 \%)$ were annotated in total, while all 269,020 unigenes $(51.47 \%)$ were annotated in at least one database according to Blastx search (Table. 1).

As for GO clustering (Fig. 4a), the dominant subcategories were, 'cellular process' and 'metabolic process' in Biological Process (BP), 'cell' and 'cell part' in Cellular Component (CC), and 'binding' in Molecular Function (MF). Regarding KEGG categorization, 41,031 annotated genes were assigned to 137 pathways belonging to 19 metabolic groups (Fig. 4c); 'carbohydrate metabolism' and 'translation' represented the 
most abundant classes in 'Metabolism'(D) and 'Genetic information processing' (C), respectively. In KOG analysis, 39,408 annotated genes were assigned to 25 groups. Among these annotated unigenes, several related to $\mathrm{N}$ reduction and assimilation were the most enriched in 'Nitrogen metabolism', and 'Alanine, Aspartate and Glutamate Metabolism' pathways abundant within the 2 macro-groups were 'translation, ribosomal structure and biogenesis' $(\mathrm{J})$ and 'posttranslational modification, protein turnover, chaperones' (0) (Fig. S1c).

To find $\mathrm{N}$ related genes, DEGs between optimal and low $\mathrm{N}$ treatments in two cultivars were compared. There were 36,432 and 45,671 DEGs between Balin and Bluemoon (BCK vs LCK, BL vs LL), and 10,156 and 838 DEGs between the optimal and low N (BCK vs BL, LCK vs LL) as shown in Venn diagram, respectively (Fig. 4b).

\subsubsection{Genes Involved In N And C-N Metabolism}

To confirm the functions of the notable transcripts in response to low $\mathrm{N}$ in two cultivars, specific DEGs with eliminating genetic background differences (Fig. 4b) were identified in Bluemoon (336) and Balin (968). KEGG analysis showed that these DEGs enriched in the pathways of 'nitrogen metabolism' (ko00910; FDR =1.06e-14), 'pyruvate metabolism' (ko00620; FDR =6.04e-06) and 'carbon fixation in photosynthetic organisms' (ko00710; FDR $=6.10 \mathrm{e}-04)$ in Bluemoon (Fig. 4d). Nevertheless, the most significantly enriched pathways were 'fatty acid elongation' (ko00062; FDR = 3.38e-05) and 'phenylpropanoid biosynthesis' (ko00940; FDR = 4.75e-03). The pathway 'nitrogen metabolism' (FDR = 0.21 ) was not significantly enriched, and no pathway related to $C$ metabolism was significantly enriched in Balin (Fig. 4e). GO enrichment was basically consistent with KEGG analysis, pathways related to $\mathrm{C} / \mathrm{N}$ metabolism 'carbon fixation' (GO: ko00062; FDR = 2.90e-08), 'carbohydrate metabolic process' (GO: 0005975; FDR = 2.03e-07), 'citrate metabolic process' (GO: 0006101; FDR =9.08e-08), 'nitrate metabolic process' (GO: 0042126; FDR = 2.09e-05) and 'nitrate assimilation' (GO: 0042128; FDR = 2.09e-05), which were notable enriched in Bluemoon (Fig. S2), but not enriched in Balin (Fig. S3).

Genes related to $\mathrm{N}$ transportation and assimilation induced by $\mathrm{N}$ starvation were differentially expressed in two cultivars. NRT2 (TRINITY_DN140116_c2_g3) encoding nitrate transporter proteins and NR (TRINITY_DN118471_c0_g1) encoding nitrate reductase were highly expressed in 'Balin' at low N stress. NiR (TRINITY_DN72083_c1_g1) encoding nitrite reductase was expressed preferentially in Balin than that in Bluemoon at optimal $\mathrm{N}$ treatment, but there was no significant differences in gene expression between two cultivars at low N stress. By contrast, GDH (TRINITY_DN129678_c2_g2) encoding glutamate dehydrogenase, GS (TRINITY_DN111472_c0_g1 and 122245_c2_g1) encoding glutamine synthetase, GOGAT (TRINITY_DN94356_c1_g2, 123883_c1_g3 and 106544_c0_g2), AspAT (TRINITY_DN115099_c0_g2 and 79352_c0_g1) encoding glutamate synthetase, aspartate aminotransferase were highly expressed in Bluemoon at low $\mathrm{N}$ status, respectively (Fig. 5a).

Since nitrate conversion to ammonium consumes one NADH and six reduced ferredoxins, and the energy needed are directly or indirectly derived from the processes of Pn, glycolysis and respiration, we examined 
several key genes involving in these $\mathrm{C}$ and $\mathrm{N}$ metabolic processes. Under low $\mathrm{N}$, gene expressions of $C A$ (TRINITY_DN137763_c1_g1 and 148777_c16_g1) encoding carbonic anhydrase, PEPC

(TRINITY_DN118112_c0_g2) encoding phosphoenolpyruvate carboxylase, ENO

(TRINITY_DN81908_c0_g1) encoding enolase, MDH (TRINITY_DN103121_c1_g1 and 76243_c1_g2)

encoding malate dehydrogenase, and $O G D H$ (TRINITY_DN117626_C0_g1 and 107170_c1_g1) encoding 2oxoglutarate (2-OG) dehydrogenase were higher in Bluemoon than that in Balin (Fig. 5a).

- 2.6 MYB DETFS expressions and roles in response to nitrogen

To better understand the roles of DETFs involved in N metabolism in KB, all DEGs were analyzed with the PlantTFDB. Finally, 1606 sequences had hits in the plant transcription factor database and were assigned into 34 families. The most frequently represented DETF families were C2H2 (13.9\%), FAR1 (7.9\%), bHLH (5.6\%), MYB (4.2\%) (Fig. S1d). 22 MYB DETFs unigenes in relation to $\mathrm{N}$ metabolism were selected from four comparisons, and were blasted against the $M Y B$ family of Brachypodium distachyum to determine their sub-family. Two of them were MYB-related types, and 13 were MYB-R2R3 types. The expression levels of DETFs analysis was confirmed by qPCR.

It was sure that the MYB transcription factor binds to the GS promoter. So, we have attained a promoter sequence (unpublished data) of GS (TRINITY_DN111472_C0_g1) via genome-walking technique. In addition to the basic components such as CAAT-box and TATA-box, a CCAAT-box along with the function of MYBHV1 (R2R3-MYB in Hordeum vulgare) binding site was also observed, its binding TFs of KB were found by blast in transcriptome (TRINITY_DN138437_c5_g1, 138437_c5_g3). The DETFs' expression levels were up-regulated in two cultivars, and the highest level expression was observed in Bluemoon. The GS promoter also contains three cis-elements including TAACCA-motif, CAACCA-motif and CCGTTG-motif that were corresponded to $M Y B$ (Fig. $5 \mathrm{~b}$ ). Therefore, we hypothesized that the trancripts (TRINITY_DN138437_c5_g1, 138437_c5_g3) in KB could bind to the promoter of GS, thereby promoting N assimilation in GS/GOGAT cycling.

\section{Discussion}

- 3.1 KB phenotypic and genetic differences in response to nitrogen

The previous study has revealed that KB possesses an aposporous pseudogamous facultative apomict and is highly variable as to reproductive, chromosomal, and phenotypic features [37], producing a complex series of polyploidy and aneuploidy genotypes including the cultivars Balin and Bluemoon. These two cultivars are distinct in morphology and chromosome ploidy, and the individual plant of Balin was relatively larger and much taller than the Bluemoon as shown in (Fig. 1). This could lead to genetic variations in $\mathrm{N}$ assimilation between the two cultivars. More interestingly, these two cultivars were from different geographical origins. Balin was from the high latitudes of Denmark, while Bluemoon was native to the low latitudes of North America, indicating that the different climatic and geographical environments in KB origins could be the vital factors involved in shaping plant morphology and even 
altering the ability of $\mathrm{N}$ physiological assimilation [38-39]. Moreover, the average $\mathrm{N}$ content in two KB cultivars were $2.1 \%$, but Bluemoon was $31.6 \%$ lower and Balin was $55.0 \%$ higher than the average (Table S1), suggesting that Balin and Bluemoon may have different strategies to adapt to $\mathrm{N}$ environments and the variations with $\mathrm{N}$ acquisition and assimilating may be maintained by vegetative propagation through a long period of the history of domestication. Transcriptome data presented in this study provided straight forward molecular information regarding the response of $\mathrm{KB}$ to $\mathrm{N}$ availability. From RNA-seq data, 79.8\% unigenes had similar levels of expression, however, 9,239 unigenes were differentially expressed under low $\mathrm{N}$ in two cultivars of KB (Fig. 4b). The results suggested that the existing genetic variations in $\mathrm{KB}$ also occurred in $\mathrm{N}$ related genes regulatory in different $\mathrm{N}$ environment.

- $3.2 \mathrm{~N}$ metabolism on the physiological and molecular regulation in KB cultivars

The result showed that the content of saturated $\mathrm{N}$ in Balin leaves was 2.3 times higher than that of Bluemoon (Fig. 2a), suggesting that more chemical substrates were cost and more energy were initiated by Balin to meet the requirement of $\mathrm{N}$ acquisition. In other word, Balin is a high $\mathrm{N}$ demand cultivar and more sensitive to $\mathrm{N}$ deficiency compared to Bluemoon. In addition, large quantities of $\mathrm{N}$ absorbed via Balin need to be transported to the aboveground to promote shoots increase and to detoxify $\mathrm{N}$ deposition, which could suggest a larger loss of $\mathrm{N}$ thru clipping removal and much less photosynthate partitioned to roots at some stages in turf management. $\mathrm{N}$ metabolism consists of $\mathrm{N}$ absorption and $\mathrm{N}$ assimilation through reduction and incorporated pathways with the aid of series of enzymes and genes [40]. The activities of $\mathrm{N}$-assimilate enzymes were induced via ambient $\mathrm{N}$ grant and were regulated by complex biochemical tactics or molecular networks [41]. In general, $\mathrm{N}$ deficiency elevated the expressions of $N R$ in Balin. At ideal N, NiR expressed plenty higher in Balin than in Bluemoon (Fig. 5a), however no variations in its expression between two cultivars at low N stress. By contrast, higher turf quality (Fig. 1e) and leaf color intensity (Fig. 1C) of Bluemoon treated with low $\mathrm{N}$ regime may additionally in part be attributed to its more efficient use of $\mathrm{N}$ though lower expression of $N R$ and NiR genes had been discovered in plants. Higher expressions of $N R$ and NiR in the course of $\mathrm{N}$ starvation in Balin accompanying with the particularly rapid decrease in $\mathrm{N}$ content may owe to its touchy to $\mathrm{N}$ supply. Another explanation may prompt their expressions by growing expression of NRT2, the high-affinity transport system gene (Fig. 5a), that may facilitate to transport $\mathrm{N}$ from the ambient for the need of assimilation. The consequences had been constant with the previous research on other plants [42]. Relatively, even though the expression of $N R$ and NiR in Bluemoon under low $\mathrm{N}$ were lower than Balin, NRT2 gene expression nevertheless increased in Bluemoon. The rationalization with this phenomenon used to be supported by using the facts that higher activities of $\mathrm{N}$ reduction enzymes which include $\mathrm{Nr}$ and $\mathrm{NiR}$ in Bluemoon than that in Balin (Fig. 2c and 2d).

In this study, each the expressions of GS, GOGAT, GDH and AspAT and the activities of GS and GOGAT have been higher in Bluemoon than that in Balin during low $N$ stress (Fig. 2e,2f and Fig. 5a), indicating that Bluemoon was more efficiency in assimilation $\mathrm{N}$ in the GS/GOGAT cycle for promoting the accumulation of glu or gln, which could be further used for compound synthesis such as the Chl or many other proteins. In addition, the R2R3-MYB DETFs, which were expected to bind to the cis-elements in the 
GS promoter of KB, had been additionally enormously expressed in Bluemoon than in Balin. The consequences indicated that the binding capacity between MYB DETFs and GS was stronger in Bluemoon than that in Balin, and this could be one of the reasons that promoted $\mathrm{N}$ assimilation in GS/GOGAT cycle and enhanced the NUE of Bluemoon in a complex signaling community at low $\mathrm{N}$ condition. Previous research have shown that R2R3-MYB TFs possess the features in improving the tolerance of Arabidopsis to abiotic stress [43]. However, the N-mediated mechanisms for these R2R3-MYB TFs in KB warrant in addition exploration.

- 3.3 The mechanism of $\mathrm{C}$ and $\mathrm{N}$ balance in $\mathrm{KB}$ cultivars in response to $\mathrm{N}$

The interconnection and interdependent processes of Pn, glycolysis, tricarboxylic acid (TCA) and GS/ GOGAT cycles in plants determine the $\mathrm{Chl}$ accumulation [44]. Therefore, the higher $\mathrm{Chl}$ content and persistence in Bluemoon may be due to the promotion of these biochemical pathways to produce aKetoglutaric acid (2-OG) and Glu, the important precursors for Chl biosynthesis [45]. In the pathway of the conversion of 2-OG and Glu, AspAT as a predominant enzyme, catalyses this reversible reaction. Interestingly, the transcriptome profiling showed that genes AspAT as well as genes GOGAT were highly expressed in Bluemoon than in Balin under low N status (Fig. 5a), which could facilitate the assimilation of glu for promoting the $\mathrm{Chl}$ synthesis. High $\mathrm{Chl}$ content in Bluemoon should be available for strength of photosynthetic light-harvesting ability, thus further enhancing its $\mathrm{Pn}$ and protecting the photosystem from photodamage via reduced photochemical conversion efficiency under low $\mathrm{N}$ condition, although the Fv/Fm of Bluemoon was higher than that of Balin during N shortage. Meanwhile, the NPQ of Bluemoon was lower than that of Balin, suggesting photophysiological and photochemical responses to $\mathrm{N}$ were more variety-specific, sand genetically altering $\mathrm{N}$ metabolism (Fig. 3). The differences in $\mathrm{N}$ reduction and assimilation and genes involved in metabolism in two KB cultivars reflected the genotypic variation at either physiological or molecular levels.

The coordinating functions of the metabolic pathways for $\mathrm{C}$ and $\mathrm{N}$ assimilation are critical for sustaining optimal growth and development for plants, and the enzymes of $\mathrm{Nr}$ and PEPc are two key points of regulators in $\mathrm{C}$ and $\mathrm{N}$ physiological integration [46]. Owing to $\mathrm{N}$ reduction is an energy-consuming process which is interdependent between $\mathrm{N}$ and $\mathrm{C}$ metabolism, the activity of $\mathrm{Nr}$ and its varied expression may be limited by the level of energy which is derived from TCA (tricarboxylic acid) cycle [47]. Meanwhile, the malate in TCA play an important role for balance the flow of energy via repression the activity of $\mathrm{Nr}$ [48]. In addition, gene PEPc not only provides a carbon source for plant photosynthesis by fixing $\mathrm{CO}_{2}$ in the atmosphere, but also replenishes the 2-OG and malate of the TCA cycle to promote $\mathrm{N}$ assimilation. Therefore, the efficiency of $\mathrm{N}$ reduction in both cultivars may directly be limited by the level of NADPH and malate which were derived from the processes of TCA, photorespiration, respiration as well as be regulated by genes involved in $\mathrm{C}-\mathrm{N}$ metabolism [47]. Our results revealed that the abundance of genes $N R$ and PEPC were conversely differential expressed between two cultivars at low $\mathrm{N}$ condition (Fig. 5a). Moreover, several other genes in $\mathrm{C}$ metabolic pathway such as $C A, E N O, P E P C, M D H$ and $O G D H$ were relatively higher enriched in Bluemoon (Fig. 5a). However, the activity of the enzyme $\mathrm{Nr}$ in Bluemoon increased rapidly and was distinctly higher than Balin under $\mathrm{N}$ deficiency, suggesting that the lower 
expression $\mathrm{C}$ metabolism related genes in Balin resulted in insufficient NADPH or ATP from C assimilation pathway for supporting $\mathrm{N}$ reduction by $\mathrm{Nr}$ under low $\mathrm{N}$. This could further lead to lower NUE and higher $\mathrm{C} / \mathrm{N}$ ratio in Balin (Fig. $2 \mathrm{~b}$ and Fig. 3e). Comparatively, Bluemoon had less leaf $\mathrm{N}$ content and higher NUE (Fig. 1e), implying that there were relatively sufficient energy derived from the $\mathrm{C}$ metabolic system for $\mathrm{N}$ reduction and glu synthesis for sustaining $\mathrm{C}$ and $\mathrm{N}$ balance in this cultivar.

\section{Conclusion}

We found much greater variation in the levels of morphological and photosynthetic characteristics, chromosomes, enzyme activities and transcript abundance of the DEGs between two KB cultivars of Bluemoon and Balin in response to $\mathrm{N}$ supply. Bluemoon was insensitive to $\mathrm{N}$ deprivation and had higher TQ, NUE, Pn and physiological $\mathrm{N}$ assimilation than Balin during chronic low $\mathrm{N}$ stress. Transcriptome sequencing revealed that several genes including GDH, AspAT, GS, GOGAT and MYB-R2R3 TFs were highly expressed in Bluemoon ether at low or optimal N, but NRT2, NR and NiR in Bluemoon expressed lower than in Balin. These genes are functionally involved in 'Nitrogen metabolism' and 'Carbon fixation in photosynthetic organisms' pathways via a whole set of interconnection and interdependent process of photosynthesis (Pn), glycolysis, tricarboxylic acid (TCA), GS/ GOGAT cycles. MYB-R2R3 were predicted to bind the promoter of GS, and may be the main mechanism to increase the efficiency of GS/GOGAT cycle, thus further enhancing the NUE in Bluemoon. Conversely, the lower expressions of $C A, E N O, P E P C, M D H$ and $O G D H$ in Balin may be the possible reason for losing NADPH from $\mathrm{C}$ assimilation pathway for supporting $\mathrm{N}$ reduction, and this could further lead to lower NUE and higher $\mathrm{C} / \mathrm{N}$ ratio in Balin. We also proposed that the different climatic and geographical environments in origins could be vital factors involved in shaping plant morphology and even alter the ability of $\mathrm{N}$ physiological assimilation. Taken together, the results here will improve our understanding of the low $\mathrm{N}$ tolerance mechanisms and the differences in $\mathrm{N}$ metabolism in KB species. This information would be valuable for the genetic improvement of NUE for creating new cultivars aiming to improve low-input turfgrass management.

\section{Declarations}

Author Contributions

CG and CY initiated and designed the research. SX and XF performed data analysis. All authors listed have made a substantial, direct, intellectural and physical contribution to the research, and approved it for publication.

Conflict of interest

The authors declare no conflict of interest.

Acknowledments 
We are grateful to Prof. Yiwei Jiang from Purdue University for the critical revision of the manuscript. This research was funded by National Natural Science Foundation of China (No 31971772; 31772354; 31372091) and College Student Innovation and Entrepreneurship Training Program of China (No 201910224035).

\section{References}

1. Szenejko M, Przemysław Śmietana E, Stpień. Genetic diversity of poa pratensis L. depending on geographical origin and compared with genetic markers. Peer J,2016;(4):e2489.

2. Gómez-Armayones C, Kvalbein A, Aamlid TS, Knox JW. Assessing evidence on the agronomic and environmental impacts of turfgrass irrigation management. J Agro Crop Sci. 2018;204(4):333-46.

3. Shah Saud S, Fahad C, Yajun, Muhammad Z, Ihsan HM, Hammad W, Nasim. et al. Effects of nitrogen supply on water stress and recovery mechanisms in KB plants. Front Plant Sci. 2017;(8):983-1001.

4. Bauer S, Lloyd D, Horgan BP, Soldat DJ. Agronomic and physiological responses of cool-season turfgrass to fall-applied nitrogen. Crop Sci. 2012;52(1):1-10.

5. Saud S. et al. Silicon Application increases drought tolerance of Kentucky bluegrass by improving plant water relations and morphophysiological functions. The Scientific World J. 2014;1-10.

6. Xu G, Fan X, Miller AJ. Plant nitrogen assimilation and use efficiency. Annu Rev Plant Biol. 2012;63(1):153-82.

7. Ashraf M, Shahzad SM, Imtiaz M, Rizwan MS. Salinity effects on nitrogen metabolism in plantsfocusing on the activities of nitrogen metabolizing enzymes: a review. J Plant Nutr. 2018;41(8):1-17.

8. Giagnoni L, Pastorelli R, Mocali S, Arenella M, Nannipieri P, Renella G. Availability of different nitrogen forms changes the microbial communities and enzyme activities in the rhizosphere of maize lines with different nitrogen use efficiency. App/ Soil Ecol. 2016;98:30-8.

9. Singh M, Singh VP, Prasad SM. Nitrogen modifies $\mathrm{NaCl}$ toxicity in eggplant seedlings: Assessment of chlorophyll a fluorescence, antioxidative response and proline metabolism. Biocat Agri Biot. 2016;7:76-86.

10. Rachana S, Parul P, Prasad SM. Sulfur and calcium simultaneously regulate photosynthetic performance and nitrogen metabolism status in as-challenged Brassica juncea L. seedlings. Front Plant Sci. 2018;9:772-90.

11. Fan K, Zhang Q, Liu M, Ma L, Shi Y, Ruan J. Metabolomic and transcriptional analyses reveal the mechanism of $\mathrm{C}, \mathrm{N}$ allocation from source leaf to flower in tea plant (Camellia sinensis. L). J. 2019;232:200-8. Plant Physiol .

12. Zhang CX, Rufty TW, Miller GL, Bowman DC. Nitrate uptake rates of Kentucky bluegrass genotypes and their effect on;nitrate absorption under competitive conditions. Crop Sci. 2013;53:1179-88.

13. Yamaya T, Kusano M. Evidence supporting distinct functions of three cytosolic glutamine synthetases and two NADP-glutamate synthases in rice. J. Exp Bot. 2014;(19),5519-5525. 
14. ZhongchunJiang, Hull R, Michaelsullivan W. Nitrate uptake and reduction in $\mathrm{C}_{3}$ and $\mathrm{C}_{4}$ grasses. $\mathrm{J}$ Plant Nutr. 2002;25:1303-14.

15. Bajgain P, Russell B, Mohammadi M. Phylogenetic analyses and in-seedling expression of ammonium and nitrate transporters in wheat. Sci Rep. 2018;8(1):7082-95.

16. Wang YY, Cheng YH, Chen KE, Tsay YF. Nitrate transport, signaling, and use efficiency. Annu Rev Plant Biol. 2018;69(1):85-122.

17. Nunes-Nesi A, Fernie AR, Stitt M. Metabolic and signaling aspects underpinning the regulation of plant carbon nitrogen interactions. Mol Plant. 2010;(6):973-996.

18. Qin X, Suga M, Kuang T, Shen JR. Structural basis for energy transfer pathways in the plant psi-lhci supercomplex. Science. 2015;348(6238):989-95.

19. Plett D, Holtham L, Baumann U, Kalashyan E, Francis K, Enju A. et al. Nitrogen assimilation system in maize is regulated by developmental and tissue-specific mechanisms. Plant Mol Biol. 2016;92(3):293-312.

20. Gaudinier A, Rodriguez-Medina J, Zhang L, Olson A, Liseron-Monfils C, Bågman AM. et al. Transcriptional regulation of nitrogen-associated metabolism and growth. Nature.2018.

21. Konishi M, Yanagisawa S. Arabidopsis NIN-like transcription factors have a central role in nitrate signalling. Nat. 2013;4:1617-26. Commun .

22. Chen S, Niu X, Guan Y, Li H. Genome-wide analysis and expression profile of the MYB genes in Brachypodium distachyon. Plant Cell Physiol. 2017;58:1777-88.

23. Bushman BS, Amundsen KL, Warnke SE, Robins JG, Johnson PG. Transcriptome profiling of kentucky bluegrass (Poa pratensis L.) accessions in response to salt stress. BMC Genom. 2016;17(1):48-60.

24. Chen $Y$, Chen $Y$, Shi Z, Jin $Y$, Sun H, Xie F. et al. Biosynthesis and signal transduction of ABA, JA, and BRs in response to drought stress of Kentucky bluegrass. Int. 2019;20(6):1289-309. J M Sci .

25. Hoagland DR. The water-culture method for growing plants without soil. California Agricultural Experiment Station Circular. 1950;347:773-5.

26. Tang Z, Yang Z, Fu S. Oligonucleotides replacing the roles of repetitive sequences pas1, psc119.2, pta-535, pta71, ccs1, and pawrc.1 for fish analysis. J Appl Genet. 2014;55(3):313-8.

27. Chen Y, Pettersen T, Kvalbein A, Aamlid TS. Playing quality, growth rate, thatch accumulation and tolerance to moss and annual bluegrass invasion as influenced by irrigation strategies on red fescue putting greens. J Agron Crop Sci. 2018;204(2):185-95.

28. Almeida Vinícius Costa

Almeida Vinícius Costa, Viana José Marcelo Soriano, Alves R L, Cleberson R, Oliveira D L R. Generation mean analysis for nitrogen and phosphorus uptake, utilization, and translocation indexes at vegetative stage in tropical popcom. Euphytica. 2018;214(7):103-115.

29. Ozawa K, Kawahigashi H. Positional cloning of the nitrite reductase gene associated with good growth and regeneration ability of calli and establishment of a new selection system for 
agrobacterium-mediated transformation in rice (Oryza sativa L.). Plant Sci. 2006;170(2):384-93.

30. Zhang C, Peng S, Peng X, Chavez AQ, Bennett J. Response of glutamine synthetase isoforms to nitrogen sources in rice (Oryza sativa L.) roots. Plant Sci. 1997;125(2):163-70.

31. Wallsgrove RM, Miflin LBJ. The development of nad(p)h-dependent and ferredoxin-dependent glutamate synthase in greening barley and pea leaves. Planta. 1982;154(5):473-6.

32. Chen YJ, Wen MX, Sui JX, Yan YQ, Yuan W, Hong L. et al. Ameliorating effects of leaf water extract of three aromatic plant species on ozone-polluted snap bean (Phaseolus vulgaris, L. 'jiangjunyoudou'). B Environ Contam Tox. 2018;100(6):849-55.

33. Testone G, Mele G. di Giacomo E, Tenore G C, Gonnella M, Nicolodi C, et al. Transcriptome driven characterization of curly- and smooth-leafed endives reveals molecular differences in the sesquiterpenoid pathway. Hortic Res. 2019;6(1):1-20.

34. Srinath T, Reddy VD, Rao KV. Isolation and functional characterization of a novel stress inducible promoter from pigeonpea (Cajanus cajan. L). Plant Cell Tiss Org. 2017;128(2):457-68.

35. Mortazavi A, Williams BA, McCue K, Schaeffer L, Wold B. Mapping and quantifying mammalian transcriptomes by RNA-SEq. Nat Methods. 2008;5(7):621-8.

36. Luo F, Cai JH, Kong XM, Zhou Q, Zhou X, Zhao YB. et al. Transcriptome profiling reveals the roles of pigment mechanisms in postharvest broccoli yellowing. Hortic Res. 2019;6(1):74-88.

37. Matzk F. The inheritance of apomixis in poa pratensis confirms a five locus model with differences in gene expressivity and penetrance. Plant Cell. 2005;17(1):13-24.

38. Perrier X, Jenny C, Bakry F, Karamura D, Kitavi M, Dubois C. et al. East African diploid and triploid bananas: a genetic complex transported from South-East Asia. Ann Bot. 2018;123:19-36.

39. Middleton BA, Travis SE, Kubátová B, Johnson D, Edwards KR. Morphology and genetics of Lythrum salicaria from latitudinal gradients of the northern hemisphere grown in cold and hot common gardens. PLoS ONE. 2019;14(1):208-32.

40. Plett D, Baumann U, Schreiber AW, Holtham L, Kalashyan E, Toubia J. et al. Maize maintains growth in response to decreased nitrate supply through a highly dynamic and developmental stage-specific transcriptional response. Plant Biotechnol. 2015;14(1):342-53. J .

41. Miller AJ, Cramer MD. Root nitrogen acquisition and assimilation. Plant Soil. 2005;274(1-2):1-36.

42. Nawaz MA, Chen C, Shireen F, Zheng Z, Sohail H, Afzal M. et al. Genome-wide expression profiling of leaves and roots of watermelon in response to low nitrogen. BMC Genom. 2018;19(1):456-75.

43. Chen S, Wu F, Li Y, Qian Y, Pan X, Li F. et al. NtMYB4 and NtCHS1 Are Critical Factors in the regulation of flavonoid biosynthesis and are involved in salinity responsiveness. Front Plant Sci. 2019;10:178.

44. Gómez-Maldonado J, Avila C, Torre F, Cañas R, Cánovas FM, Campbell MM. Functional interactions between a glutamine synthetase promoter and MYB proteins. Plant J. 2004;39:513-26.

45. Xu B, Li H, Li Y, Yu G, Zhang J, Huang B. Characterization and transcriptional regulation of chlorophyll b, reductase gene NON-YELLOW COLORING 1, associated with leaf senescence in perennial ryegrass (Lolium perenne, L.). Environ Exp Bot. 2018;149:43-50. 
46. Rochaix JD. Regulation and dynamics of the light-harvesting system. Annu. 2014;65(1):287-309. R Plant Biol .

47. Argueso CT, Ferreira FJ, Kieber JJ. Environmental perception avenues: the interaction of cytokinin and environmental response pathways. Plant Cell Environ. 2010;32(9):1147-60.

48. Patricia Müller, Li X, Niyogi KK. Non-photochemical quenching. a response to excess light energy. Plant Physiol. 2001;125(4):1558-66.

\section{Tables}

Due to technical limitations, Tables 1-2 are provided in the Supplementary Files section.

\section{Figures}
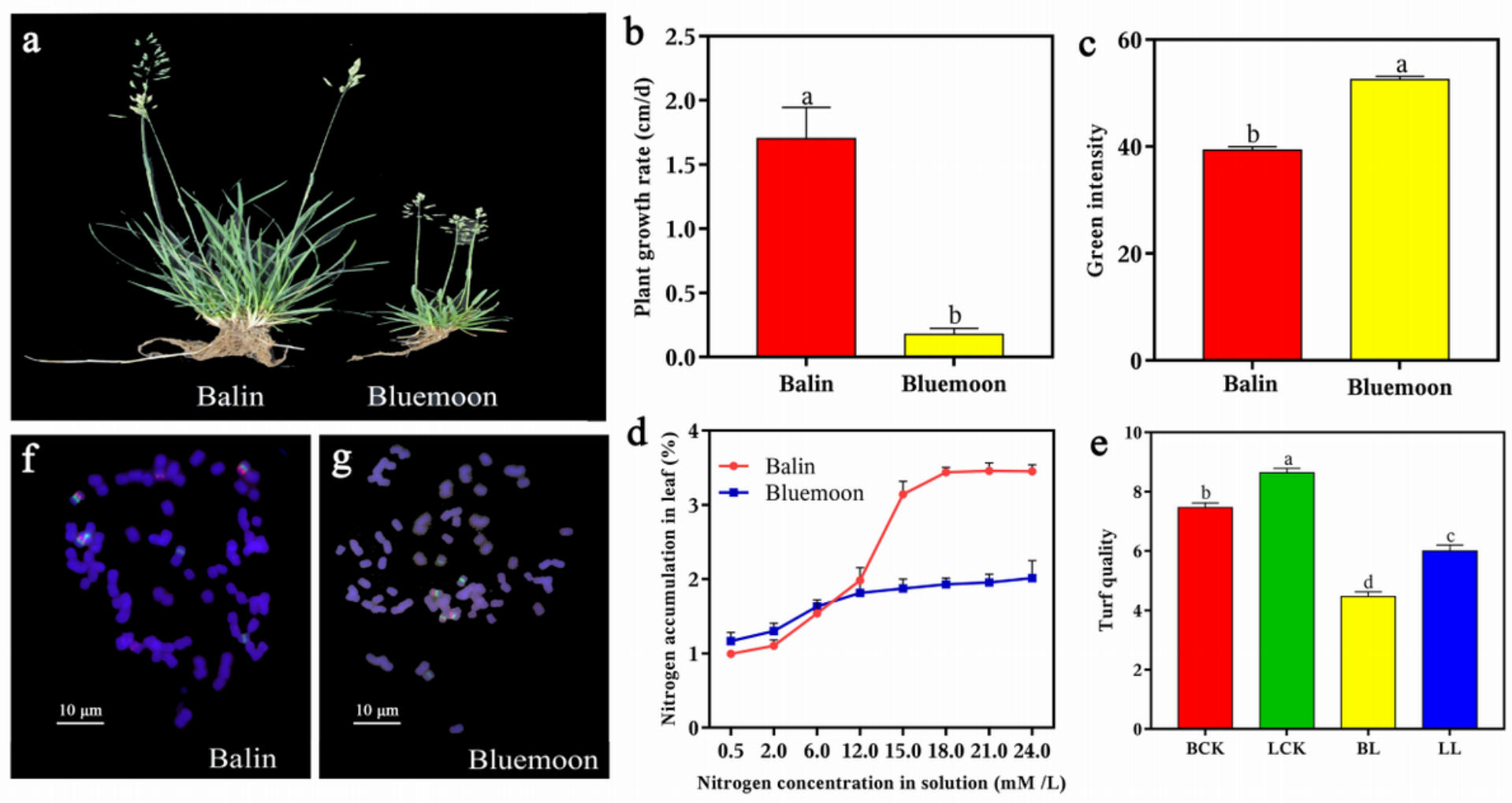

\section{Figure 1}

Differences of phenotype, chromosome and turf impression between Balin and Bluemoon. Fig. 1a Morphological characteristics of Balin and Bluemoon; Fig. 1b Plant growth rate of Balin and Bluemoon; Fig. 1c Leaf color intensity Balin and Bluemoon. Fig. $1 \mathrm{~d} \mathrm{~N}$ accumulation patterns and $\mathrm{N}$ content in Balin and Bluemoon; Fig. 1e Turf quality at $\mathrm{N}$ treatments; Fig. $1 \mathrm{f}$ and $1 \mathrm{~g}$ Chromosome numbers of Balin and Bluemoon. Vertical bars indicate least significant difference values $(P \leq 0.05)$ among treatments $(n=3)$. (BCK=Balin under optimal $\mathrm{N}$ treatment; $\mathrm{BL}=$ Balin under low $\mathrm{N}$ treatment; $\mathrm{LCK}=$ Bluemoon under optimal $\mathrm{N}$ treatment; $\mathrm{LL}=\mathrm{Bluemoon}$ under low $\mathrm{N}$ treatment. The same as following figures). 

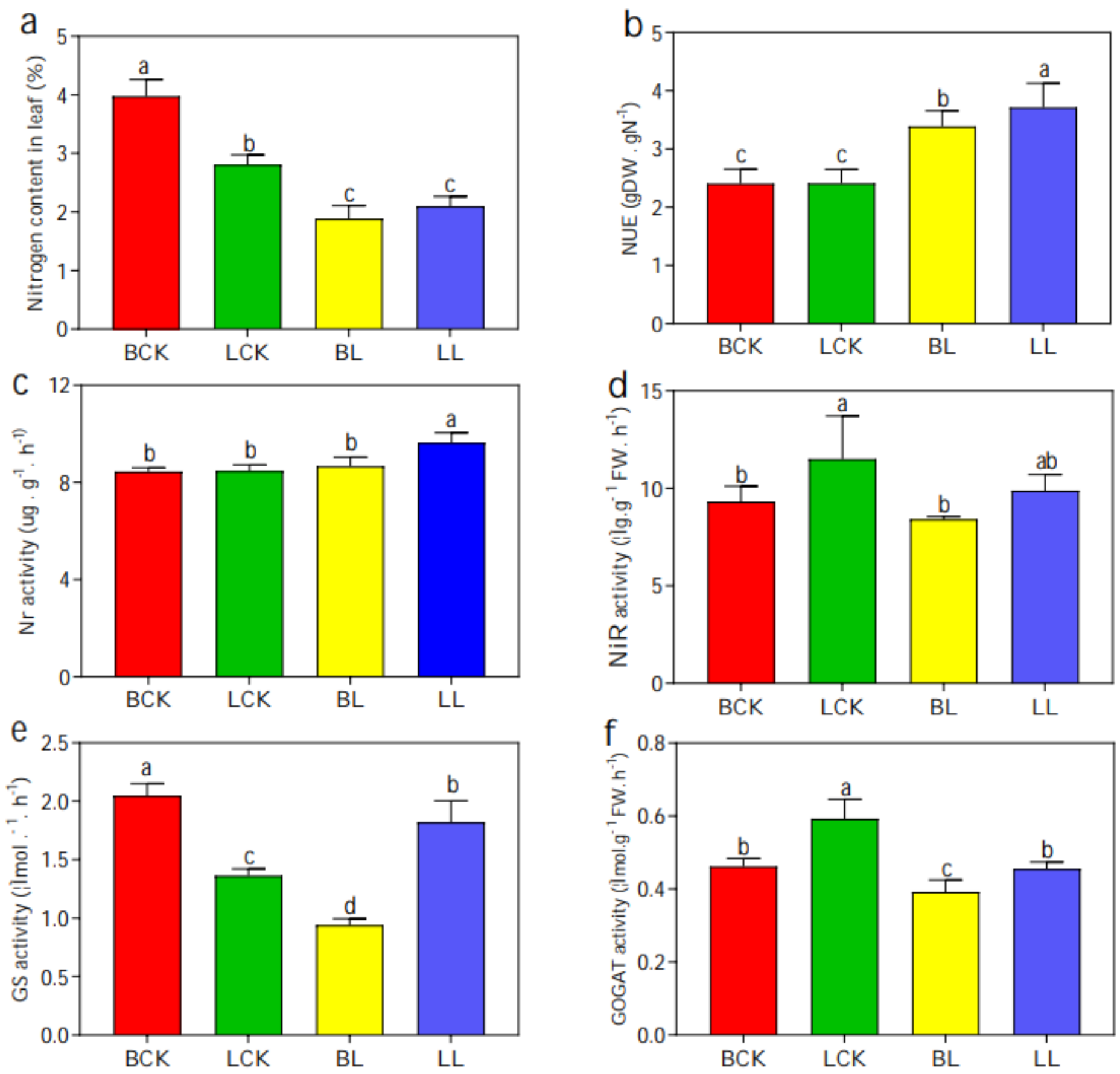

Figure 2

Enzymes involving in $\mathrm{N}$ metabolism in Balin and Bluemoon in response to $\mathrm{N}$ treatments. Fig. 2a, 2b, 2c, $2 d, 2 e$ and $2 f$ represent the changes of $N$ content, $N$ use efficiency (NUE), nitrate reductase (NR), nitrite reductase (NiR), glutamine synthetase (GS), and glutamate synthetase (GOGAT) activities respectively. 

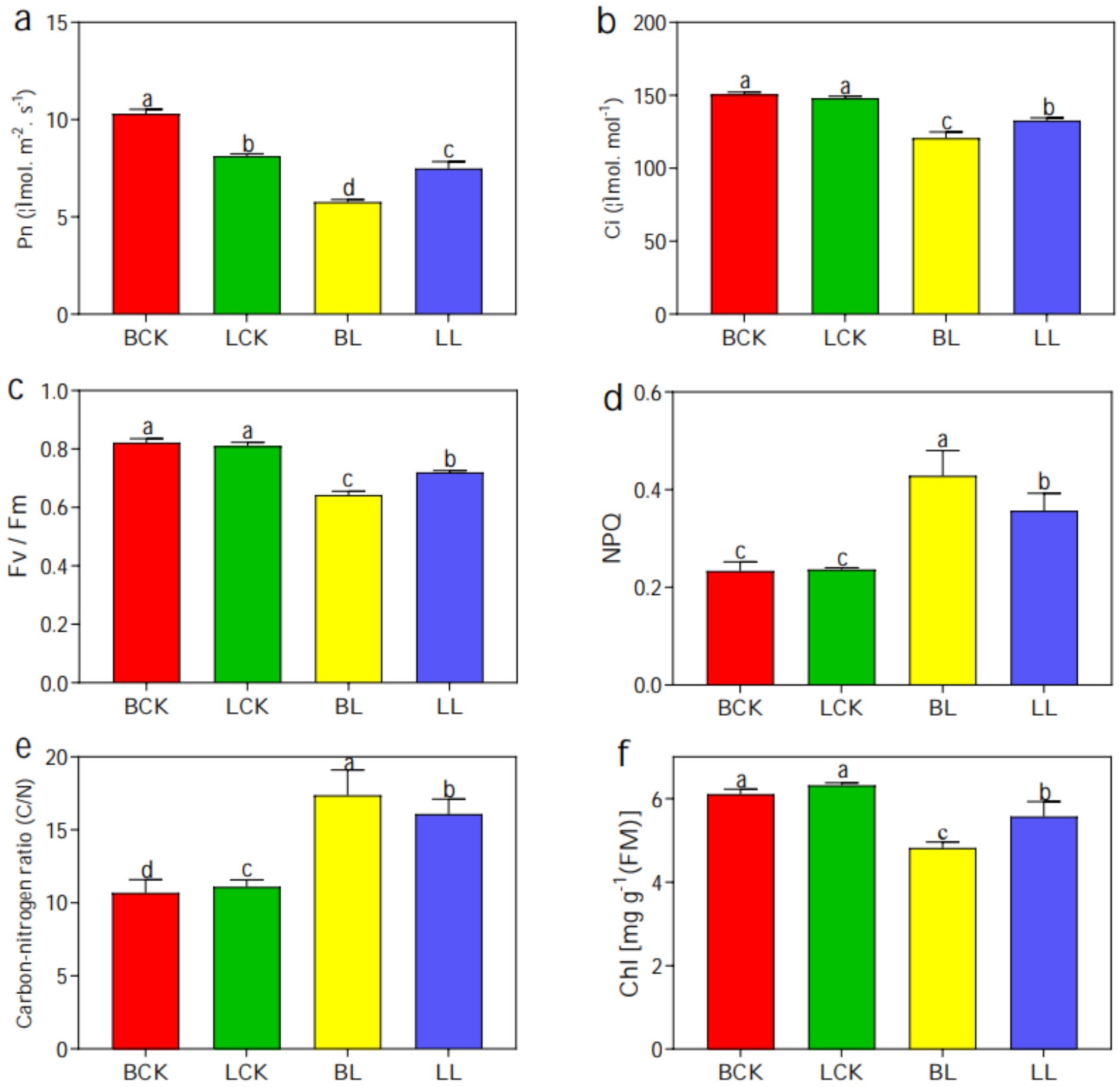

Figure 3

Photosynthesis parameters in Balin and Bluemoon in response to $\mathrm{N}$ treatments. Fig. 3a, 3b, 3c, 3d, 3e and $3 \mathrm{f}$ represent the changes of photosynthetic assimilation (Pn), intercellular $\mathrm{CO} 2(\mathrm{Ci})$, maximum photosynthetic efficiency (Fv/Fm), the nonphotochemical quenching (NPQ), carbon-nitrogen ratio (C/N) and chlorophyll (Chl) content respectively. Table 1 Unigene information annotated in different databases in Kentucky bluegrass leaves induced by nitrogen 


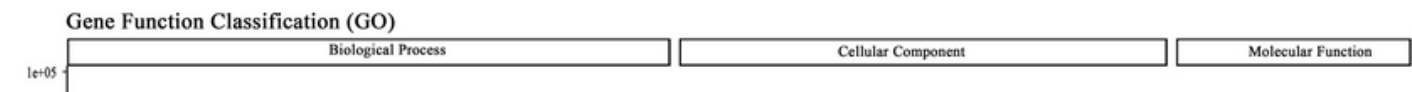

b
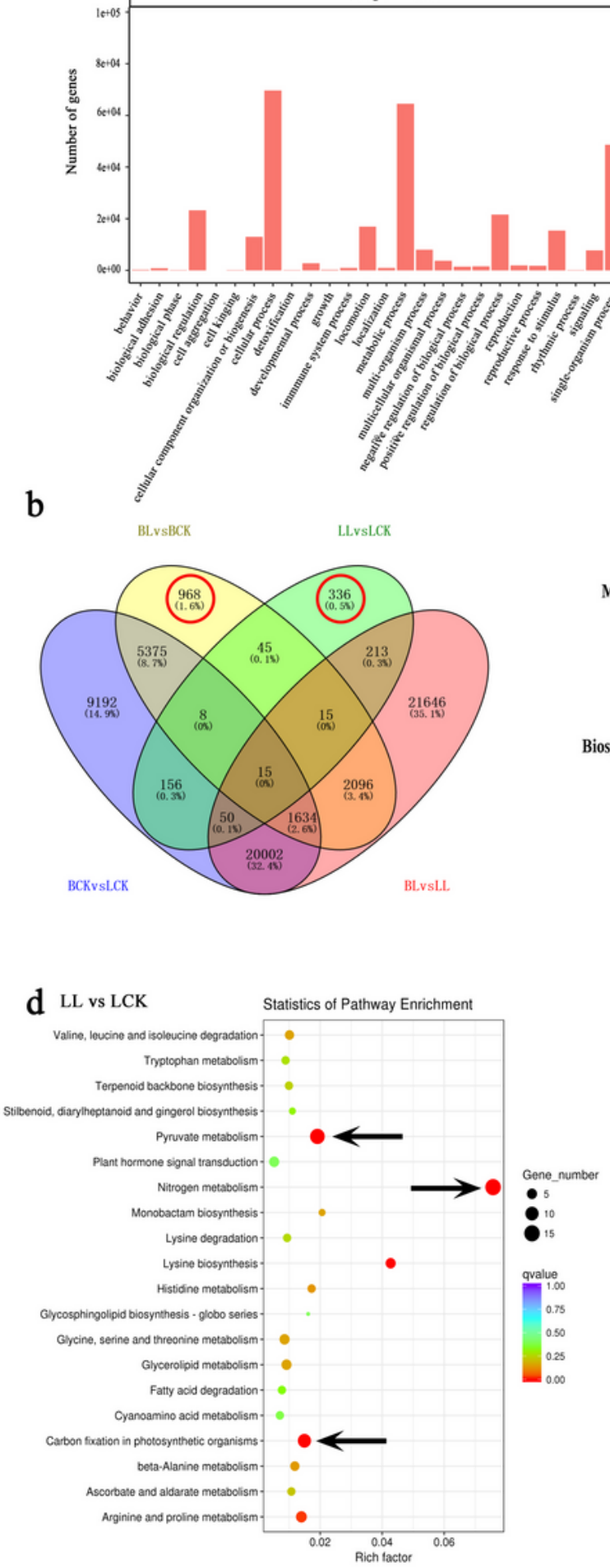

c
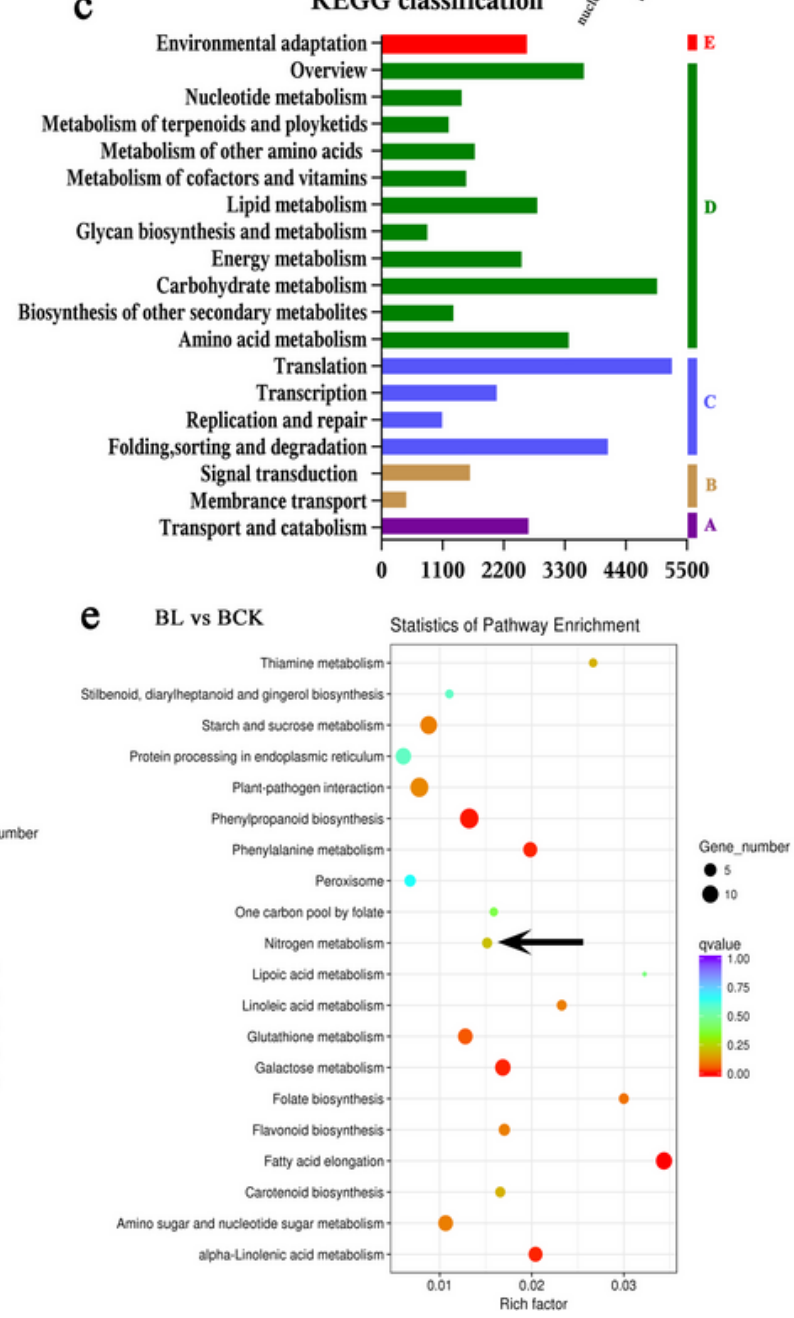

\section{Figure 4}

Overview the RNA sequencing of Balin and Bluemoon in response to $\mathrm{N}$ treatments. Fig. $4 \mathrm{a}$ GO classification. The $\mathrm{GO}$ terms were classified into biological process, cellular component, and molecular function; Fig. 4b Venn diagram of the numbers of differentially expressed genes (DEGs) among four pairwise comparisons. Fig. 4c KEGG classification A, cellular processes; B, environmental information 
process; $C$, genetic information processing; D, metabolism; E, organismal systems. Fig. 4d and 4e KEGG classification of 336 and 968 DEGs enriched in metabolic pathways.

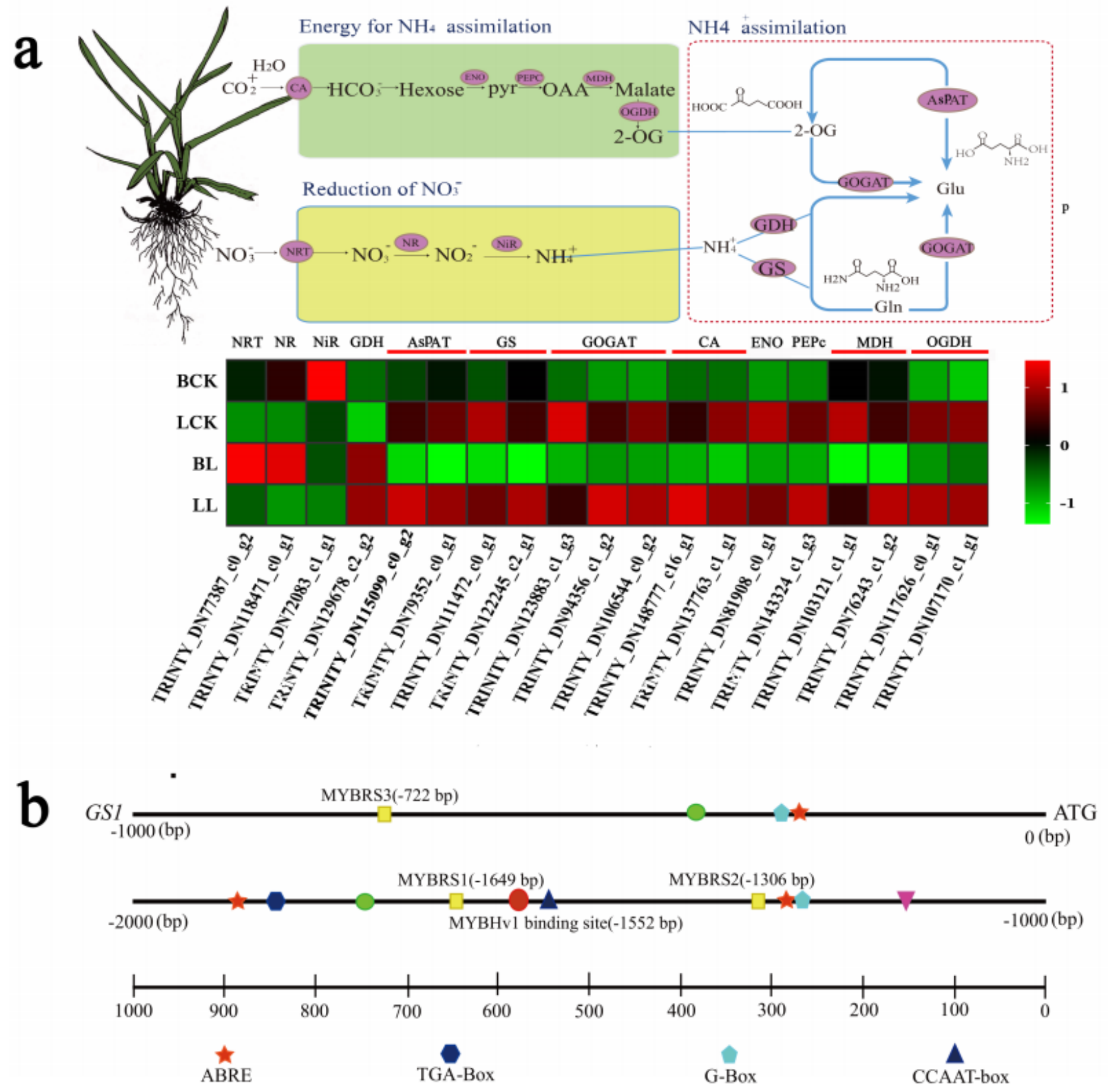

Figure 5

Expressions of DEGs in nitrogen metabolic network and MYB biding domain with GS promoter. Fig. 5 a. The pathways of nitrate assimilation and the energy NADH for nitrate reduction which was generated via Calvin cycle, Glycolysis and TCA cycle. Fig. 5b. Three MYB recognition sites and one binding site contained in the GS promoter. Table 2. Uingenes of differentially expressed transcription factors and DEG analysis 

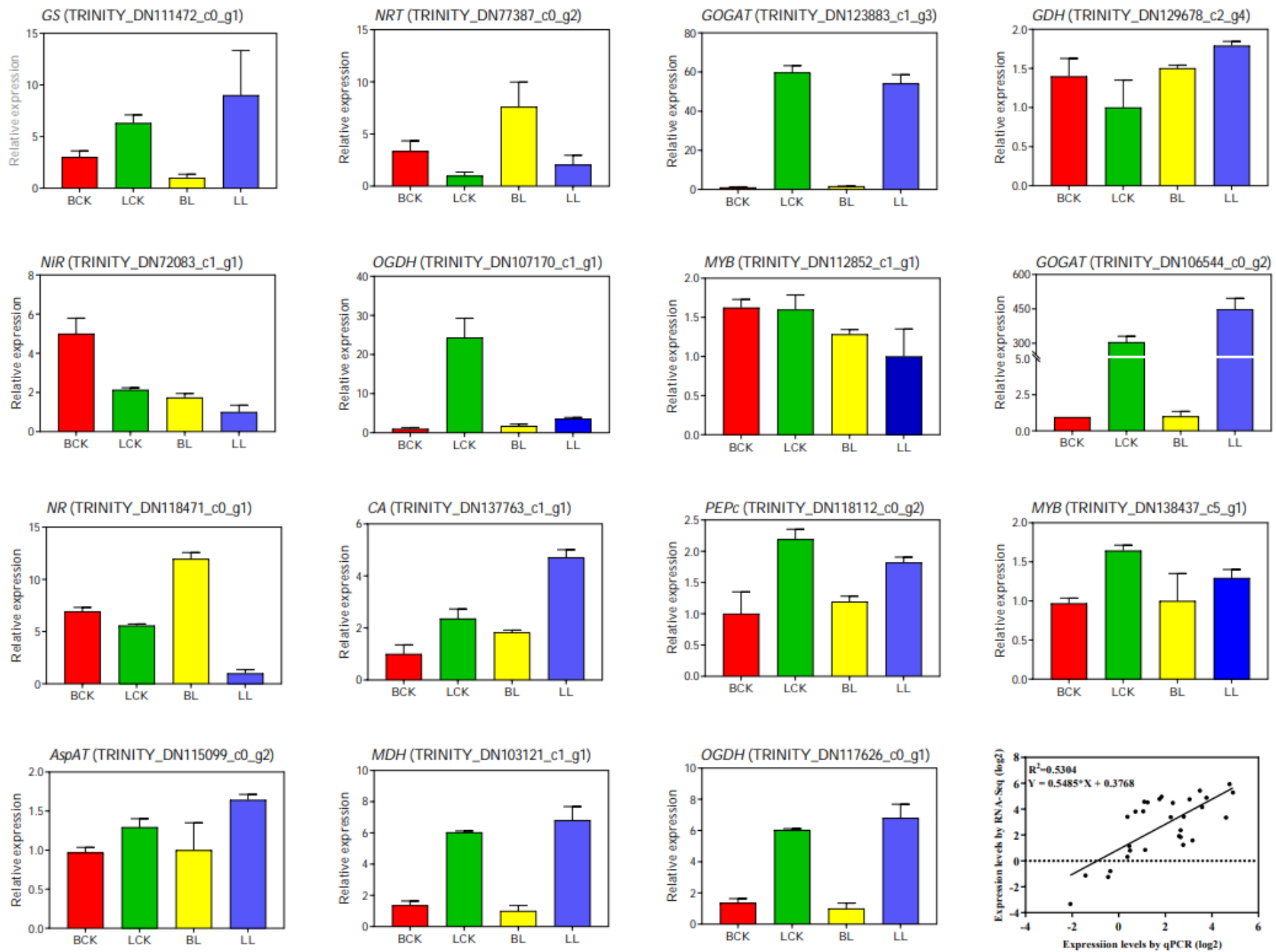

Figure 6

qRT-PCR validation of key candidate DEGs in Balin and Bluemoon at different $\mathrm{N}$ treatments.

\section{Supplementary Files}

This is a list of supplementary files associated with this preprint. Click to download.

- Table1.xlsx

- Table2.xls

- Supplementarylnformation.docx 